\title{
UM OLHAR MINERALÓGICO - O PERFIL DO QUARTZO E SUAS PROPRIEDADES FÍSICAS
}

\author{
A mineralogical look - quartz profile and your physical properties
}

Una vista mineralógica - el perfil de cuarzo y sus propiedades físicas

\begin{abstract}
Michel Gomes de Freitas Vandervilson Alves Carneiro **

* Licenciado em Química, Universidade Estadual de Goiás, Campus Henrique Santillo, Anápolis (GO) michelgomesfreitas@hotmail.com

** Orientador e Docente, Universidade Estadual de Goiás, Campus Henrique Santillo, Anápolis (GO) vandervilson.carneiro@ueg.br
\end{abstract}

Recebido em 08/10/2019. Aceito para publicação em 20/10/2019.

Versão online publicada em 10/11/2019 (http://seer.ufrgs.br/paraonde)

\begin{abstract}
Resumo:
A Mineralogia é um ramo da Geologia que estuda a natureza e a formação dos minerais da crosta terrestre. Dentre os minerais estudados estão os quartzos $\left(\mathrm{SiO}_{2}\right)$ que são abundantes em território brasileiro e em Goiás tem áreas significativas como o caso de Cristalina que surgiu a partir de extrativismo rudimentar do cristal de rocha: são garimpados a céu aberto, comercializados, processados e utilizados em uma gama de produtos industriais. Os quartzos são prismáticos, trigonais, monocristalinos, policristalinos, estão presentes nos grupos rochosos (sedimentares, ígneos e metamórficos) e apresentam propriedades físicas de destaque. O objetivo principal foi o de analisar o perfil e as propriedades físicas do quartzo conforme os manuais de Mineralogia para auxiliar a disciplina de Fundamentos de Mineralogia no Curso de Licenciatura em Química. Os procedimentos metodológicos foram: pesquisa bibliográfica, visita técnica à SEGEP (UEG-CCET), seleção e manuseio das amostras de quartzo, registro fotográfico, análise e descrição das amostras de quartzo conforme os manuais de Mineralogia. Esse conhecimento e essa análise elencados tanto do perfil como das propriedades físicas do quartzo alicerçam os estudos de Mineralogia e Geologia e que permitem a utilização dos dados em aulas nos cursos de licenciaturas em Química e Geografia, da Universidade Estadual de Goiás, Campus Henrique Santillo, Anápolis (GO).
\end{abstract}

Palavras-chave: Ensino de Geociências. Minerais. Escala de Mohs. $\mathrm{SiO}_{2}$.

\begin{abstract}
:
Mineralogy is a branch of Geology that studies the nature and formation of minerals in the earth's crust. Among the minerals studied are quartz $\left(\mathrm{SiO}_{2}\right)$ which are abundant in brazilian territory and in Goiás there are significant areas such as Crystalline which arose from rudimentary extraction of rock crystal: they are mined in the open air, marketed, processed and used in a range of industrial products. Quartz are prismatic, trigonal, monocrystalline, polycrystalline, present in rock groups (sedimentary, igneous and metamorphic) and have outstanding physical properties. The main objective was to analyze the profile and physical properties of quartz according to the Mineralogy manuals to help the discipline of Fundamentals of Mineralogy in the Degree Course in Chemistry. The methodological procedures were: literature search, technical visit to SEGEP (UEG-CCET), selection and handling of quartz samples, photographic record, analysis and description of quartz samples according to the Mineralogy manuals. This knowledge and analysis of both the profile and the physical properties of quartz underpin the studies of Mineralogy and Geology and allow the use of data in classes in undergraduate courses in Chemistry and Geography at the State University of Goiás, Henrique Santillo Campus, Anápolis (GO).
\end{abstract}

Key-words: Teaching Geosciences. Minerals. Mohs scale. $\mathrm{SiO}_{2}$. 


\begin{abstract}
Resumen:
La mineralogía es una rama de la geología que estudia la naturaleza y la formación de minerales en la corteza terrestre. Entre los minerales estudiados están el cuarzo $\left(\mathrm{SiO}_{2}\right)$, que es abundante en el territorio brasileño, y en Goiás hay áreas significativas como el Cristalino, que surgió de la extracción rudimentaria del cristal de roca: se extraen al aire libre, se comercializan, se procesan y se utilizan en una serie de productos industriales. El cuarzo es prismático, trigonal, monocristalino, policristalino, presente en grupos rocosos (sedimentarios, ígneos y metamórficos) y tiene propiedades físicas excepcionales. El objetivo principal fue analizar el perfil y las propiedades físicas del cuarzo según los manuales de Mineralogía para ayudar a la disciplina de Fundamentos de Mineralogía en la carrera de Química. Los procedimientos metodológicos fueron: búsqueda bibliográfica, visita técnica a la SEGEP (UEG-CCET), selección y manejo de muestras de cuarzo, registro fotográfico, análisis y descripción de muestras de cuarzo según los manuales de Mineralogía. Este conocimiento y análisis tanto del perfil como de las propiedades físicas del cuarzo sustentan los estudios de Mineralogía y Geología y permiten el uso de datos en clases de pregrado en Química y Geografía en la Universidad Estatal de Goiás, Campus Henrique Santillo, Anápolis (GO).
\end{abstract}

Palabras-clave: Enseñanza de las Geociencias. Minerales. Escala de Mohs. $\left(\mathrm{SiO}_{2}\right)$.

\title{
1 Introdução
}

$\mathrm{Na}$ UEG - Universidade Estadual de Goiás, Campus Henrique Santillo, município de Anápolis / GO, mais precisamente no Curso de Licenciatura em Química, a disciplina de Fundamentos de Geologia, com carga-horária de 60 h, da matriz curricular de 2015, contempla o conteúdo de Mineralogia e é ministrada semestralmente.

Então, "a Mineralogia, como parte das Geociências que trata dos minerais, abrange um universo de mais que 4.000 espécies distintas, número este que vem crescendo a cada ano em 40-50 novas espécies", conforme Branco e Chaves (2006, p. 76).

Os pesquisadores Andrade e Del Lama (2007, p. 48) concordam com Dutrow (2004) e Dyar (2004) que os "estudos sobre o Ensino de Geociências indicam que a Mineralogia é tipicamente a primeira disciplina dos currículos de cursos de Geologia [, de Geografia e de Química] a tratar em profundidade temas relacionados às Ciências da Terra".

Nunes e Nóbrega Junior (2009, p. 6) afirmam que "os geólogos definem um mineral como uma substância de massa inorgânica natural, geralmente sólida e cristalina, de composição química definida, com um ou vários tipos de cristalização". Continuam pontuando que "os minerais são os constituintes básicos das rochas que formam a litosfera" e a "rocha [é definida] como um conjunto de minerais ou apenas como um mineral consolidado. Logo, as rochas podem ser identificadas pelos minerais que as integram" (NUNES; NÓBREGA JUNIOR, 2009, p. 6).

Nesse prisma, "Mineralogia é a ciência que estuda a natureza e a formação dos minerais, englobando as propriedades físicas, químicas e físico-químicas dos mesmos, bem como, a classificação e descrição das espécies minerais", conforme Nunes e Nóbrega Junior (2009, p. 6).

Cabe informar que os minerais necessitam serem ordenados ou classificados de acordo com princípios científicos para racionalizar o estudo. Despertou-se o interesse pelo perfil e propriedades físicas do quartzo, pois esse mineral é

ParaOnde!?, Porto Alegre, v.12 n.2, p.49-58, 2019. http://seer.ufrgs.br/paraonde Edição Especial - III Colóquio de Pesquisadores em Geografia Física Ensino de Geografia 
abundante na cascalheira do Cerrado e também foi visto e relatado em trabalhos de campo realizados pela disciplina de Fundamentos de Geologia.

A proposta de trabalho tem como objetivo principal analisar o perfil e as propriedades físicas do quartzo conforme os manuais de Mineralogia para auxiliar a disciplina de Fundamentos de Geologia nos cursos de licenciaturas em Química e em Geografia.

\section{A geologia e o ramo da mineralogia}

O Glossário Geológico do IBGE (1999, p. 94) diz que a Geologia é a "ciência que estuda o globo terrestre desde o momento em que as rochas se formaram até 0 presente". Em outro momento, Toledo (2002, não paginado) relata que "podemos definir [a] Geologia como a ciência cujo objeto de estudo é a Terra: sua origem, seus materiais, suas transformações e sua história". Mineralogia:

Em referência à Geologia Teórica e/ou à Geologia Física, encontra-se a

Ramo das Ciências da Terra que estuda os minerais e que está intimamente ligada à física e à química. Sendo a definição de mineral, a de uma substância natural, de composição química estabelecida entre determinados limites e estrutura atômica bem definida, são especialmente as propriedades físicas e químicas que permitem a sua identificação e estudo (IGM, 2001, não paginado).

Concordando com Nickel (1995), um mineral trata-se de um composto químico que é normalmente cristalino e que foi formado como resultado de processos geológicos.Também "chama-se mineral a um cristal natural e inorgânico com uma estrutura interna cristalina, com composição química bem definida (fixa ou variável entre certos limites também bem definidos) e podendo assumir a forma de um poliedro" (IGM, 2001, não paginado).

No caso dos minerais, eles apresentam propriedades: físicas (quadro 1), químicas (quadro 2) e ópticas que permitem a sua caracterização e identificação.

\section{Quadro 1 - Propriedades Físicas dos Minerais}

\begin{tabular}{|l|l|}
\hline Clivagem & $\begin{array}{l}\text { Propriedade que alguns minerais têm de se fragmentarem } \\
\text { segundo determinadas superfícies planas e paralelas. A estas } \\
\text { superfícies planas chama-se plano de clivagem. }\end{array}$ \\
\hline Dureza & $\begin{array}{l}\text { A dureza é a resistência que o mineral oferece a ser riscado por } \\
\text { outro mineral ou objeto alternativo. A dureza depende do tipo de } \\
\text { ligações químicas presentesnomineral,ouseja,quantomaisfortes } \\
\text { forem estas ligações maior dureza terá o mineral. }\end{array}$ \\
\hline Brilho & $\begin{array}{l}\text { O brilho dos minerais é o modo como estes refletem a luz } \\
\text { incidente nas suas superfícies, de preferência as não alteradas. }\end{array}$ \\
\hline Cor & $\begin{array}{l}\text { A cor dos minerais é a característica mais fácil de observar, e } \\
\text { pode ser muito importante, quando é típica de um mineral, mas }\end{array}$ \\
\hline
\end{tabular}

ParaOnde!?, Porto Alegre, v.12 n.2, p.49-58, 2019. http://seer.ufrgs.br/paraonde Edição Especial - III Colóquio de Pesquisadores em Geografia Física Ensino de Geografia 


\begin{tabular}{|c|l|}
\hline há o caso de minerais que podem apresentar várias cores. \\
Resulta da absorção de algumas radiações da luz branca que \\
incide sobre o mineral.
\end{tabular}

\section{Quadro 2 - Propriedades Químicas dos Minerais}

\begin{tabular}{|ll|}
\hline Elementos nativos & $\begin{array}{l}\text { São os minerais que ocorrem na natureza em estado puro, } \\
\text { não combinado - como o ouro,prata, cobre, enxofre, } \\
\text { diamante, grafita. }\end{array}$ \\
\hline Sulfuretos & $\begin{array}{l}\text { Minerais metálicos de que são exemplos: a pirita, } \\
\text { calcopirita, galena, blenda (esfalerita). }\end{array}$ \\
\hline & $\begin{array}{l}\text { Minerais comuns, sobretudo nos ambientes mais } \\
\text { superficiais da Terra, de que fazem parte entre muitos } \\
\text { outros a hematita, goethita, pirolusita e magnetita. }\end{array}$ \\
\hline
\end{tabular}

ParaOnde!?, Porto Alegre, v.12 n.2, p.49-58, 2019. http://seer.ufrgs.br/paraonde Edição Especial - III Colóquio de Pesquisadores em Geografia Física Ensino de Geografia 


\begin{tabular}{|l|l|}
\hline Halóides & $\begin{array}{l}\text { Classe restrita que reúne os halogenetos naturais como a } \\
\text { halita, silvita, fluorita. }\end{array}$ \\
\hline $\begin{array}{l}\text { Carbonatos, Nitratos } \\
\text { e Boratos são caracterizados por ter um grupo aniônico no qual } \\
\text { o átomo de carbono, nitrogênio ou boro está rodeado por } \\
\text { três átomos de oxigênio. Nitratos e boratos são bastante } \\
\text { raros na natureza, os carbonatos são bastante } \\
\text { abundantes. Exemplos: calcita, dolomita, malaquita, } \\
\text { rodocrosita e outros. }\end{array}$ \\
\hline Silicatos & $\begin{array}{l}\text { São os minerais mais abundantes da crosta terrestre e são } \\
\text { próprios das rochas endógenas (magmáticas e } \\
\text { metamórficas) embora apareçam em rochas sedimentares. } \\
\text { Como exemplos:olivina, turmalina, piroxênios, anfibolitos, } \\
\text { biotita e outras. }\end{array}$ \\
\hline
\end{tabular}

Fonte: IGM (2001).

Com relação às propriedades ópticas dos minerais, o estudo e a observação é muito importante, mas também muito complexo, pois só assim, pode-se estudar minerais que formam as rochas mesmo quando são tão pequenos que não se vê a olho nu. Nesta ocasião, para se observar as rochas e os minerais pelo microscópio petrográfico torna-se necessário cortá-los em lâminas delgadas muito finas com 0,03 $\mathrm{mm}$ de espessura para que a luz transmitida do microscópio possa atravessá-los (IGM, 2001).

Nos contextos da Mineralogia e da Geologia, a fase estável da sílica $\left(\mathrm{SiO}_{2}\right)$ à temperatura ambiente, conhecida como quartzo - $\alpha$, é um dos minerais mais abundantes da crosta terrestre, cerca de $12 \%$. Ela ocorre na composição de rochas magmáticas, sedimentares e metamórficas, na forma monocristalina (quartzo hialino, ametista, citrino e outros), na forma policristalina (quartzito, calcedônia e ágata) e amorfa (opala). O quartzo - a tem hábito prismático piramidal, pertence ao sistema trigonal e sua classe de simetria cristalina é a 32. Por possuir poucos elementos de simetria, as propriedades físicas do quartzo - $\alpha$ dependem fortemente da orientação cristalográfica (FRONDEL, 1962; GUZZO, 2008; MACHADO et al., 2017).

O relatório do perfil do quartzo da J. Mendo Consultoria (2009, p. 3) descreve que "o Brasil é o país que detém as maiores reservas mundiais de quartzo. Porém, como muitas das empresas operam no regime de garimpo e de forma muito rudimentar, elas não têm base tecnológica para agregar valor e explorar toda a potencialidade de uso domineral".

Destaca também que:

O quartzo tem seu uso selecionado por sua qualidade. Os cristais de melhor qualidade são destinados à indústria óptica, eletrônica e de instrumentação (considerados os maiores consumidores), enquanto os de qualidade inferior destinam-se à indústria em geral (abrasivos, cerâmica, metalúrgica) (J. MENDO CONSULTORIA, 2009, p. 3).

O relatório pontua que "as principais reservas mundiais de quartzo se encontram no Brasil e, em volumes menores, em Madagascar". No cenário brasileiro, "em termos de produção de quartzo em cristal merecem destaques os

ParaOnde!?, Porto Alegre, v.12 n.2, p.49-58, 2019. http://seer.ufrgs.br/paraonde Edição Especial - III Colóquio de Pesquisadores em Geografia Física Ensino de Geografia 
estados da Bahia, Minas Gerais, Goiás, Paraná, Rio de Janeiro, São Paulo e Santa Catarina". É descrito também que "na produção brasileira de quartzo predomina o pequeno minerador e o minerador informal (não legalizado), tanto na produção de lascas (fragmentos de quartzo selecionados manualmente pesando menos de 200 gramas) quanto na produção de cristais". Continua informando que "os cristais de grau eletrônico (usados na indústria de cristal cultivado) são mais raros e de produção esporádica" (J. MENDO CONSULTORIA, 2009, p.4).

Conforme Rocha (2014, p. 1),

Sabe-se, no entanto, que o Brasil é detentor de 95\% das reservas mundiais, o equivalente a 78 milhões de toneladas. No Estado do Pará estão as maiores reservas medidas do país, [com] cerca de 64\% das jazidas, seguidas de $17 \%$ em Minas Gerais, 15\% em Santa Catarina e 2\% na Bahia e $2 \%$ em Goiás.

Exatamente no interior de Goiás, [...] [encontra-se a cidade de Cristalina], [...] um município de 54.337 habitantes, que se destaca pela grande ocorrência do mineral quartzo no subsolo e até mesmo na superfície da cidade, que está sob uma camada de [...] quartzos [...] (NOGUEIRA, 2016, não paginado.). Os pesquisadores Barbosa (1955) e Faria (1985) concordam que o município de Cristalina (GO) está assentado em uma estrutura geológica denominada de domo quartzítico.

Entende-se que a região se caracteriza por estar dentro de um domo estrutural de grandes proporções onde as rochas sedimentares do Grupo Paranoá foram elevadas e arqueadas criando uma bela estrutura circular, o Domo de Cristalina. E este evento criou uma zona de alívio de tensão que propiciou uma forte atividade hidrotermal, responsável pelas inúmeras minas e ocorrências de cristais de quartzo, o que dá o nome da cidade. A altitude geral do domo é em torno de 1.200 metros (O PORTAL DO GEÓLOGO, 2018, não paginado).

O relatório de J. Mendo Consultoria (2009, p. 3) aponta que:

A lavra de quartzo no Brasil se dá em minas a céu aberto, ou subterrâneas de pequena profundidade. Pode-se dizer que a tecnologia é rudimentar e a proporção é extremamente pequena do material utilizável em relação ao quartzo existente no depósito. A mecanização da explotação de quartzo é complexa visto a necessidade de se evitar danos na estrutura do cristal por quebra. Já no caso de extração de lascas, a mecanização pode se estender muito se as jazidas forem contínuas.

Assim, "apesar de possuir as maiores reservas mundiais de quartzo de alta qualidade, o setor está pulverizado em garimpos", como o caso de Cristalina (GO). "A demanda por quartzo tem sido muito sensível às mudanças tecnológicas" e [...] [um caminho possível e promissor em longo prazo, é justamente o de [...] "se dominar a tecnologia dos produtos finais do quartzo, [pois, em anos vindouros, poderá [...] influenciar o mercado [mineral] e evitar grandes variações [financeiras]" (J. MENDO CONSULTORIA (2009, p. 3).

ParaOnde!?, Porto Alegre, v.12 n.2, p.49-58, 2019. http://seer.ufrgs.br/paraonde Edição Especial - III Colóquio de Pesquisadores em Geografia Física Ensino de Geografia 


\section{Metodologia}

A pesquisa bibliográfica foi desenvolvida a partir de materiais publicados em livros, revistas impressas e eletrônicas, dissertações e teses. Ela pode ser realizada independentemente ou pode constituir parte de uma pesquisa descritiva ou experimental.

Também contou com uma visita à SEGEP - Seção de Geologia e Paleontologia, da UEG - Universidade Estadual de Goiás / CCET - Campus de Ciências Exatas e Tecnológicas Henrique Santillo (Anápolis - GO), pois, foi de extrema importância como ferramenta de ensino para o professor, auxiliando-o na condução das aulas, e o que é mais importante, permitindo ao aluno o contato com a aplicação prática dos conteúdos de Geologia e Mineralogia aprendidos em sala de aula. Na SEGEP, da UEG-CCET, ocorreu o manuseio das amostras de minerais, ou seja, dos quartzos para descrição e análise do perfil e das propriedades físicas conforme os manuais geológicos e mineralógicos.

O registro fotográfico das amostras de quartzo foi adotado como uma forma apropriada de documentar e alicerçar a pesquisa monográfica em si.Com o apoio da pesquisa bibliográfica, da visita técnica e do registro fotográfico desenvolveu-se a análise das informações e o processamento descritivo tanto do perfil como das propriedades físicas dos quartzos.

\section{Resultados e discussão}

Nesse grupo de minerais, destacam-se os quartzos da SEGEP (UEG-CCET), pois, segundo Guzzo (2008, p. 683) "o quartzo - a tem hábito prismático piramidal, pertence ao sistema trigonal e sua classe de simetria cristalina é a 32" (figura 1).

Figura 1 - Amostras de quartzos da SEGEP (UEG-CCET)

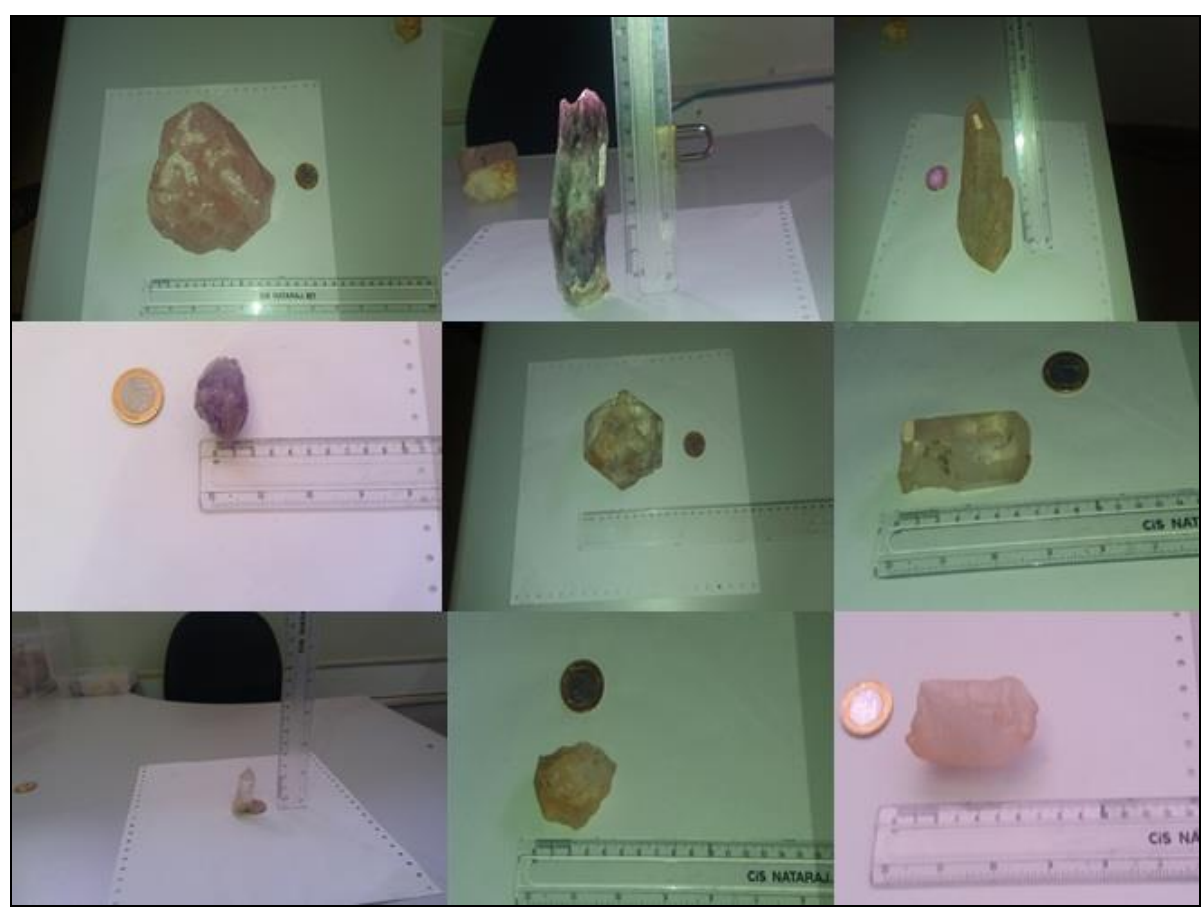

Fonte: Michel Gomes de Freitas (2018)

ParaOnde!?, Porto Alegre, v.12 n.2, p.49-58, 2019. http://seer.ufrgs.br/paraonde Edição Especial - III Colóquio de Pesquisadores em Geografia Física Ensino de Geografia 
Conforme os estudos de Frondel (1962) e de Carvalho (2008), os quartzos analisados encaixam-se na Escala de Dureza de Mohs com valor 7,0. São frágeis e não possuem planos de clivagem pelo fato de suas estruturas possuírem uma cadeia tridimensional de tetraedros $\mathrm{SiO} 4$ interligados. Os aspectos morfológicos das superfícies fraturadas dos quartzos são caracterizados como conchoidais ou subconchoidais.

Os quartzos da SEGEP (UEG-CCET) estão em conformidade com os apontamentos de Guzzo (2008, p. 689), onde:

A coloração é o parâmetro empregado para classificar as variedades de quartzo natural. A maior parte dos cristais tem aspecto opaco devido às inclusões e fissuras internas, sendo denominado quartzo leitoso. O quartzo hialino ou cristal de rocha é incolor e possui grande transparência. As outras variedades de quartzo são a ametista de cor violeta, o quartzo esfumaçado, com diferentes intensidades de escurecimento, o quartzo negro ou murion, o citrino (amarelo e amarelo/esfumaçado), o quartzo róseo, o quartzo azul e o quartzo verde (prásio). O quartzo hialino é transparente em uma ampla faixa do espectro eletromagnético, desde o ultravioleta próximo $(\lambda=300 \mathrm{~nm})$ até o infravermelho próximo $(\lambda=2000 \mathrm{~nm})$.

Nota-se também que os quartzos estudados apresentam uma densidade que varia entre 2,6 a $2,65 \mathrm{~g} / \mathrm{cm}^{3}$, pertencem à família dos tectossilicatos e são minerais de composição química $\mathrm{SiO}_{2}$, além de possuírem fortes propriedades piezoelétricas e piroelétricas (KLEIN; DUTROW, 2012; CARVALHO, 2008).

\section{Considerações finais}

O Estado de Goiás é um dos produtores de quartzo do país, contribuindo com $2 \%$, que servem tanto para utilização industrial como para comercialização in natura, ornamentação, souvenirs, etc em cidades turísticas (Caldas Novas, Cidade de Goiás, Pirenópolis e outras), em cidades oriundas de atividades mineradoras (Cristalina e outras) e também como amostras para coleções com fins museológicos e acadêmicos.

Nesse contexto acadêmico, os referidos quartzos que são abundantes na cascalheira do Cerrado e em antigos garimpos abandonados podem ser utilizados em aulas de Geologia e Mineralogia com ênfase em suas propriedades físicas e outras estabelecidas conforme o plano de ensino. Cabe mencionar a título de sugestão, a confecção/montagem de um pequeno mostruário com quartzos e sua diversidade de cores para uso em sala de aula.

Essa temática quartzosa rende muito assunto, mas os cristais geminados e biterminados, como cristais solitários, drusas e cristais gigantes também são peças desejadas por museus, laboratórios de Geologia e Mineralogia, pesquisadores e colecionadores.

O caso de Cristalina (GO) é peculiar, pois, surge do garimpo de cristais de rocha que definhou ao longo do tempo e sua economia atual está embasada no capital agrário. Assim, entende-se que o governo estadual deveria incentivar e encarar os pequenos garimpeiros que persistem nessa atividade e também as lojas de souvenirs com um olhar voltado ao turismo.

ParaOnde!?, Porto Alegre, v.12 n.2, p.49-58, 2019. http://seer.ufrgs.br/paraonde Edição Especial - III Colóquio de Pesquisadores em Geografia Física Ensino de Geografia 
Nessa linha, espera-se ter contribuído com mais informes sobre o quartzo e que novos artigos possam ser elaborados. Menciona-se também que esse texto deverá ser submetido brevemente a uma revista acadêmica.

\section{Referências}

ANDRADE, F. R. D.; DEL LAMA, E. A. Mineralogia: disciplina básica e profissionalizante. Revista do Instituto de Geociências - USP, São Paulo, v. 4, p. 47- 51, 2007.

BARBOSA, O. Guia de excursões do IX Congresso Brasileiro de Geologia (noticiário 3). Rio de Janeiro: SBG, 1955.

BRANCO, P. M.; CHAVES, M. L. S. C. A mineralogia e alguns de seus minerais raros ou de gênese exótica. Terrae Didática, Campinas, v. 2, n. 1, p. 75-85, 2006.

CARVALHO, A. M. G. Introdução ao estudo dos minerais. Lisboa: Âncora, 2008.

DUTROW, B. L. Teaching mineralogy from the core to the crust. Journal of Geoscience Education, Washington, v. 52, n. 1, p. 81-86, 2004.

DYAR, M. D. Integration of new methods in teaching mineralogy. Journal of Geoscience Education, Washington, v. 52, n. 1, p. 23-30, 2004.

FARIA, A. Geologia do domo de Cristalina, Goiás. Revista Brasileira de Geociências, São Paulo. 15, n. 3, p. 231-240, set. 1985.

FRONDEL, C. The system of mineralogy: silica minerals. New York: John Wiley \& Sons, 1962.

GUZZO, P. L. Quartzo. In: LUZ, A. B.; LINS, F. F. Rochas e minerais industriais: usos e especificações. Rio de Janeiro: CETEM, 2008. p. 681-721.

INSTITUTO BRASILEIRO DE GEOGRAFIA E ESTATÍSTICA - IBGE. Glossário geológico. Rio de Janeiro: IBGE - DIBIS, 1999.

INSTITUTO GEOLÓGICO E MINEIRO - IGM. Litoteca de portas abertas. 2001. Disponível em: <http://www.Ineg.pt/CienciaParaTodos/edicoes_online/diversos/guiao_litoteca/texto>. Acesso em: 12 set. 2017.

J. MENDO CONSULTORIA. Mineração brasileira: quartzo. Brasília: MME / BIRD, 2009.

KLEIN, C.; DUTROW, B. Manual de ciência dos minerais. Porto Alegre: Bookman, 2012.

ParaOnde!?, Porto Alegre, v.12 n.2, p.49-58, 2019. http://seer.ufrgs.br/paraonde Edição Especial - III Colóquio de Pesquisadores em Geografia Física Ensino de Geografia 
MACHADO, F. B.; MOREIRA, C. A.; ZANARDO, A; ANDRE, A. C.; GODOY, A. M.; FERREIRA, J. A.; GALEMBECK, T.; NARDY, A. J. R.; ARTUR, A. C.; OLIVEIRA, M. A. F. Enciclopédia multimídia de minerais (quartzo). Disponível em: <http://www.rc.unesp.br/museudpm/banco/silicatos/tectossilicatos/quartzo.html>. Acesso em: 08 nov. 2017.

NICKEL, E. H. The definition of a mineral. The Canadian Mineralogist, Vancouver, v. 33, n. 3, p. 689-690, 1995.

NOGUEIRA, B. Cristalina: a cidade dos cristais. Revista Mineração \& Sustentabilidade, Betim, dez. 2016. Disponível em: <http://revistamineracao.com.br/2016/12/02/cristalina-a-cidade-dos-cristais/>. Acesso em: 25 mai. 2018.

NUNES, E.; NÓBREGA JUNIOR, O. B. Minerais e rochas. Brasília: UFRN / UEPB, 2009.

O PORTAL DO GEÓlOGO. O domo de Cristalina. Disponível em: <http://www.geologo.com.br/pedradochapeu2.asp>. Acesso em: 25 mai. 2018.

ROCHA, G. A. Quartzo (cristal). 2014. Disponível em: <http://www.anm.gov.br/dnpm/sumarios/quartzo-sumario-mineral-2014>. Acesso em: 25 mai. 2018.

TOLEDO, M. C. M. O que é a geologia?. 2002. Disponível em: <http://www.igc.usp.br/index.php?id=158>. Acesso em: 21 nov. 2017. 